\title{
Effect of alloxan-induced diabetes on serum and cardiac butyrylcholinesterases in the rat
}

\author{
K R Dave and S S Katyare \\ Department of Biochemistry, Faculty of Science, Maharaja Sayajirao University of Baroda, Vadodara 390 002, India \\ (Requests for offprints should be addressed to K R Dave who is now at Department of Neurology (D4-5), PO Box 016960, University of Miami School of \\ Medicine, Miami, Florida 33101, USA; Email: krdave@stroke.med.miami.edu)
}

\begin{abstract}
Elevated serum butyrylcholinesterase (BChE) activity in the diabetic rat, mouse and human is very evident. The source of the increased level of BChE in the diabetic condition is not known. The effect of diabetes on cardiac $\mathrm{BChE}$ has not been studied so far, in spite of high BChE levels in the heart. In the present study, we investigated the effect of alloxan-induced diabetes on serum and on the soluble as well as the membrane-bound form of cardiac BChE activity and their substrate kinetics. We included rats of both sexes in the study. Serum BChE activity increased only in male diabetic rats (2.3-fold), while the activities of the soluble as well as the membrane-bound form of cardiac BChE activity increased 2.2- to $2 \cdot 8$-fold in male diabetic rats. A smaller increase $(30 \%)$ was observed
\end{abstract}

in the activity of the membrane-bound form of cardiac $\mathrm{BChE}$ in female diabetic rats. A slight reduction in $\mathrm{BChE}$ activity was observed in male and female rats after insulin treatment. The activity ratio of the soluble to the membrane-bound form of cardiac BChE was higher in diabetic and insulin-treated diabetic rats as compared with controls. The $K_{\mathrm{m}}$ values of component II of the serum and soluble forms of cardiac BChE were comparable. In conclusion, the diabetes-induced increase in serum and cardiac BChE activity was sex dependent. Insulin was not able to rectify the diabetes-induced abnormalities in serum and cardiac BChE activity. The heart could be one of the possible sources of the increased level of serum BChE.

Journal of Endocrinology (2002) 175, 241-250

\section{Introduction}

Vertebrates possess two cholinesterases corresponding to two distinct genes: acetylcholinesterase (AchE; EC 3.1.1.7) and butyrylcholinesterase (BchE; EC 3.1.1.8). The two enzymes are distinguished primarily on the basis of their substrate specificity (Massoulie et al. 1993). AChE is thought to participate in the hydrolysis of acetylcholine, terminating its physiological action (Chatonnet \& Lockridge 1989, Massoulie et al. 1993). The function of $\mathrm{BChE}$ remains a puzzle. It has been shown that $\mathrm{BChE}$ is involved in the degradation of succinylcholine (a myorelaxant used in surgical operations), hydrolysis of drugs such as heroin, detoxification of plant esters and phytotoxins ingested in the diet, regulation of plasma choline levels, and in lipid/lipoprotein metabolism (Funnel \& Oliver 1965, Kutty 1980, Lockridge et al. 1980, Valentino et al. 1981, Shirai et al. 1988, 1991).

A rise in serum $\mathrm{BChE}$ activity in the diabetic rat, mouse and human $(22 \%-270 \%)$ has been reported (Kutty et al. 1981, Patel et al. 1990, Annapurna et al. 1991, Oreskovic \& Kunec-Vajic 1992, Abbott et al. 1993). BChE activity was also found to be increased significantly in the plasma, pancreas and adipose tissue (33-100\%) of alloxan-induced diabetic rats (Oreskovic \& Kunec-Vajic 1992). BChE activity was found to be higher in all tissues in control female rats when compared with control male rats. Oreskovic \& Kunec-Vajic (1992) also observed similar sex differences in $\mathrm{BChE}$ activity under diabetic conditions. It has been shown that the rise in $\mathrm{BChE}$ activity in plasma is not related to the level of $\mathrm{BChE}$ production in the liver. It has been speculated that adipose tissue might be a site of synthesis of increased levels of serum BChE (Kutty 1980).

The increase in serum BChE activity might be a response to hypertriglyceridemia or it might reflect a decreased removal from the circulation as a consequence of diabetic renal microangiopathy (Patel et al. 1990). A positive correlation was found between serum $\mathrm{BChE}$ activity and serum triacylglycerol concentrations in hypertensive patients, obese patients and patients with hypercholesterolemia and hyperlipoproteinemia (Cucuianu et al. 1975, Chu et al. 1978, Magarian \& Dietz 1987). The injection of heparin appears to activate lipoprotein lipase in diabetic rats, shown by a marked fall in serum triglyceride and total low density lipoprotein levels but not in $\mathrm{BChE}$ activity (Annapurna et al. 1991). A relationship between serum lipid/lipoprotein metabolism and BChE activity in diabetes lacks any strong supportive evidence.

This literature survey thus reveals that a rise in serum BChE activity in the diabetic condition is very evident, 
but the source of the increased levels of $\mathrm{BChE}$ is still unknown. Surprisingly, the effect of diabetes on cardiac BChE has not been studied as yet, even though the heart in higher vertebrates is one of the tissues containing a large amount of BChE. In the adult hearts of higher vertebrates, $85 \%$ of total cholinesterase is BChE and only $15 \%$ is AChE (Chatonnet \& Lockridge 1989).

In view of the above, the main objective of the present study was to investigate the effect of alloxan-induced diabetic and insulin-treated alloxan-induced diabetic conditions on serum and cardiac BChE activity. For easy comparison between different isoforms of $\mathrm{BChE}$ in serum and heart, substrate kinetics were also studied. Because of reports showing a sex-dependent effect of diabetes on BChE activity, we included rats of both sexes in the present study.

\section{Materials and Methods}

\section{Chemicals}

Butyrylthiocholine iodide (BCTI) and Triton X 100 were purchased from Sigma Chemical Co., St Louis, MO, USA. 5,5' Dithio-bis (2-nitrobenzoic acid) (DTNB) was purchased from SRL (Mumbai, India) and NPH insulin from Knoll Pharmaceuticals Ltd (Ahmedabad, India). All other chemicals were of analytical reagent grade and were purchased locally.

\section{Animals}

Male and female albino rats of the Charles Foster strain weighing between 180 and $220 \mathrm{~g}$ were used. After fasting for $24 \mathrm{~h}$ the animals were given a single s.c. injection of freshly prepared alloxan solution using saline $(0 \cdot 9 \%(\mathrm{w} / \mathrm{v})$ $\mathrm{NaCl}$ ) as vehicle, at a dose of $12 \mathrm{mg}$ alloxan/100 g body weight (Bahnak \& Gold 1982). The control animals received saline vehicle only. The diabetic state was ascertained in terms of loss of body weight, polyuria, glycosuria, polydipsia, polyphagia and blood glucose levels (Nerurkar et al. 1988). Symptoms of diabetes were observed within a week of alloxan injection. One group of animals was used as a diabetic group (no treatment). Another group of diabetic animals received NPH insulin s.c. at a dose of 8 $\mathrm{U} / \mathrm{kg}$ body weight twice daily for 7 days consecutively starting at the end of 22 days of alloxan treatment (Nerurkar et al. 1988); the last dose of insulin was given $12 \mathrm{~h}$ prior to killing the animals. This group was used as the insulin-treated diabetic group. At the end of 1 month after treatment with alloxan or vehicle, animals were killed. The protocol was approved by the Departmental Animal Ethics Committee.

\section{Separation of serum}

The blood was collected and allowed to clot at room temperature and serum was collected after centrifugation at $475 \mathrm{~g}$ for $8 \mathrm{~min}$ in a clinical centrifuge. The strawcolored supernatant was carefully decanted.

Isolation of soluble and membrane-bound forms of BChE from the heart

Isolation of soluble and membrane-bound forms of $\mathrm{BChE}$ from the heart was achieved essentially by following the procedure of Bisso et al. (1991) as described earlier (Dave et al. 2000, 2002). Briefly, the tissue (heart) from male and female rats of all groups was quickly removed after decapitation and placed in beakers containing chilled $\left(0-4{ }^{\circ} \mathrm{C}\right) 38 \mathrm{mM}$ Tris- $\mathrm{HCl}$ buffer at $\mathrm{pH} 8 \cdot 5$. The tissues were repeatedly washed with the same buffer to remove blood and $10 \%(\mathrm{w} / \mathrm{v})$ homogenates were prepared using a Potter-Elvehjem type glass-teflon homogenizer. The supernatant obtained after centrifugation at $100000 \boldsymbol{g}$ for $1 \mathrm{~h}$ was used as the source of the soluble form of the enzyme. The pellet was extracted in the same volume of $38 \mathrm{mM}$ Tris- $\mathrm{HCl}$ buffer, $\mathrm{pH} 8 \cdot 5$, containing $0 \cdot 25 \%$ Triton X-100 and after centrifugation at $100000 \boldsymbol{g}$ for $1 \mathrm{~h}$ the supernatant was used as the source of the membranebound enzyme. All the operations were carried out at $0-4{ }^{\circ} \mathrm{C}$.

\section{Assay of BChE activity}

The enzyme activities were determined according to the method of Ellman et al. (1961), with some modifications (Dave et al. 2000, 2002). The assay mixture contained in a volume of $1.0 \mathrm{ml}$ was $50 \mathrm{mM}$ Tris- $\mathrm{HCl}$ buffer, $\mathrm{pH} 8 \cdot 0$, containing $0.38 \mathrm{mM}$ DTNB; $10-50 \mu \mathrm{g}$ protein served as a source of tissue enzymes, while $5-10 \mu \mathrm{l}$ serum was used as the source of the enzyme for serum. The linear rate of reaction recorded over a period of $60-90 \mathrm{~s}$ at $37^{\circ} \mathrm{C}$ was used for calculation of the rate of the reaction. The DTNB solution was prepared by dissolving $10 \mathrm{mg}$ DTNB $+5 \mathrm{mg}$ $\mathrm{NaHCO}_{3}$ in $10 \mathrm{ml}$ Tris- $\mathrm{HCl}$ buffer (Dave et al. 2000, 2002).

For substrate kinetic studies, the concentration of BCTI ranged from $0 \cdot 05$ to $10 \mathrm{mM}$ in serum and 0.2 to $10 \mathrm{mM}$ in the soluble and membrane-bound forms of the heart. For substrate kinetics, the data were analyzed by the Lineweaver-Burk, Eadie-Hofstee and Eisenthal CornishBowden methods for the determination of apparent $K_{\mathrm{m}}$ and apparent $V_{\max }$ (Dixon \& Webb 1979). Due to limitations in these methods of analysis, the $K_{\mathrm{m}}$ and $\mathrm{V}_{\max }$ values presented in the present study are considered to be apparent. The values of apparent $K_{\mathrm{m}}$ and apparent $\mathrm{V}_{\max }$ obtained by the three methods of analysis were in close agreement and were averaged. The values are given as means \pm S.E.M. Analyses of substrate kinetics data were carried out by employing Sigma Plot, Version 5.0 (Dave et al. 2000, 2002).

Protein was estimated by the method of Lowry et al. (1951) using bovine serum albumin as the standard. 
Table 1 Physiological parameters in alloxan-treated rats. Results are expressed as means \pm S.E.M. of the number of independent observations indicated in parentheses

\begin{tabular}{|c|c|c|c|c|}
\hline & Sex & Control (16) & Diabetic (16) & $\begin{array}{l}\text { Insulin-treated } \\
\text { diabetic (13) }\end{array}$ \\
\hline \multicolumn{5}{|l|}{ Parameter } \\
\hline \multirow[t]{2}{*}{ Body weight (g) } & Male & $248 \pm 9$ & $183 \pm 6^{* *}$ & $245 \pm 6^{b}$ \\
\hline & Female & $243 \pm 7$ & $174 \pm 6^{* *}$ & $221 \pm 10^{b}$ \\
\hline \multirow[t]{2}{*}{ Body sugar (mM) } & Male & $5.9 \pm 1.6$ & $24 \pm 2^{* *}$ & $4 \cdot 8 \pm 0 \cdot 3^{b}$ \\
\hline & Female & $6 \cdot 7 \pm 0 \cdot 5$ & $37 \pm 4 \cdot 4^{* *}$ & $8 \cdot 1 \pm 0 \cdot 3^{b}$ \\
\hline \multirow{2}{*}{ Urine volume/day (ml) } & Male & $2 \cdot 5 \pm 0 \cdot 2$ & $43 \pm 5 \cdot 4^{* *}$ & $2 \cdot 2 \pm 0 \cdot 4^{b}$ \\
\hline & Female & $2 \cdot 9 \pm 0 \cdot 4$ & $47 \cdot 0 \pm 4 \cdot 1^{* *}$ & $3 \cdot 1 \pm 0 \cdot 5^{b}$ \\
\hline \multirow[t]{2}{*}{ Sugar (mg/ml urine) } & Male & N.D. & $26 \pm 1 \cdot 6$ & N.D. \\
\hline & Female & N.D. & $15 \pm 0 \cdot 6$ & N.D. \\
\hline \multirow[t]{2}{*}{ Sugar excretion (g/day) } & Male & - & $1 \cdot 1 \pm 0 \cdot 1$ & - \\
\hline & Female & - & $0 \cdot 76 \pm 0.07$ & - \\
\hline \multirow[t]{2}{*}{ Heart weight (g) } & Male & $0.67 \pm 0.08$ & $0.52 \pm 0.02$ & $0.68 \pm 0.02^{b}$ \\
\hline & Female & $0.45 \pm 0.02$ & $0 \cdot 46 \pm 0 \cdot 04$ & $0.66 \pm 0.02^{* * b}$ \\
\hline \multirow{2}{*}{$\begin{array}{l}\text { Heart weight (\% of } \\
\text { body weight) }\end{array}$} & Male & $0 \cdot 28 \pm 0 \cdot 01$ & $0 \cdot 29 \pm 0 \cdot 01$ & $0 \cdot 28 \pm 0 \cdot 01$ \\
\hline & Female & $0 \cdot 21 \pm 0 \cdot 01$ & $0 \cdot 27 \pm 0 \cdot 01^{* *}$ & $0.30 \pm 0.02^{* *}$ \\
\hline
\end{tabular}

N.D., not detectable.

${ }^{*} P<0.005$ compared with corresponding control; ${ }^{b} P<0.005$ compared with corresponding diabetic.

Table 2 Effect of alloxan-induced diabetes on serum BChE activity ( $\mathrm{nmol} / \mathrm{min}$ per $\mathrm{ml}$ serum) in male and female rats. BCTI ( $4 \mathrm{mM})$ was used as substrate in the assay. Results are expressed as means \pm S.E.M. of the number of independent observations indicated in parentheses

\begin{tabular}{|c|c|c|c|}
\hline \multirow[b]{2}{*}{ Sex } & Control & Diabetic & Insulin-treated diabetic \\
\hline & & & \\
\hline Male & $215 \pm 10(9)$ & $497 \pm 45(10)^{* *}$ & $394 \pm 31(7)^{* *}$ \\
\hline Female & $941 \pm 95(9)$ & $958 \pm 83(10)$ & $888 \pm 90(7)$ \\
\hline
\end{tabular}

Protein yield was comparable in soluble and membranebound forms of the heart in all experimental and control groups. Statistical evaluation of the data was performed using the Student's $t$-test.

\section{Results}

Effect of alloxan-induced diabetes on physiological parameters

Polyuria, glycosuria and hyperglycemia were observed in diabetic male and female rats (Table 1). Insulin treatment of diabetic animals was able to control these characteristics of diabetes in both sexes.

\section{Elevated serum BChE activity in diabetic males but not in females}

Our aim was to study serum BChE activity in diabetic and insulin-treated diabetic male and female rats. The serum BChE activity was higher by $4 \cdot 4$-fold in the control female rats when compared with the control male rats (Table 2 ).
In the diabetic male rats, the serum $\mathrm{BChE}$ activity was higher by $2 \cdot 3$-fold $(P<0 \cdot 005)$ and remained elevated $(1 \cdot 8$-fold, $P<0 \cdot 005)$ after insulin treatment when compared with the control group. A statistically nonsignificant decreasing trend (21\%) in serum BChE activity was observed in insulin-treated diabetic male rats when compared with the diabetic male group. By contrast, in females no statistically significant differences were found in BChE activity among three groups, i.e. control, diabetic and insulin-treated diabetic.

In brief, the $\mathrm{BChE}$ activity in control female rats was higher than in the control males. The serum $\mathrm{BChE}$ activity was higher in diabetic and insulin-treated diabetic male rats. Diabetes or insulin treatment had no effect on serum BChE activity in the female rats.

\section{Effect of alloxan-induced diabetes on substrate kinetics of} serum $B C h E$

In view of the dramatic changes in serum BChE activity, we extended our studies and looked at the substrate kinetic 

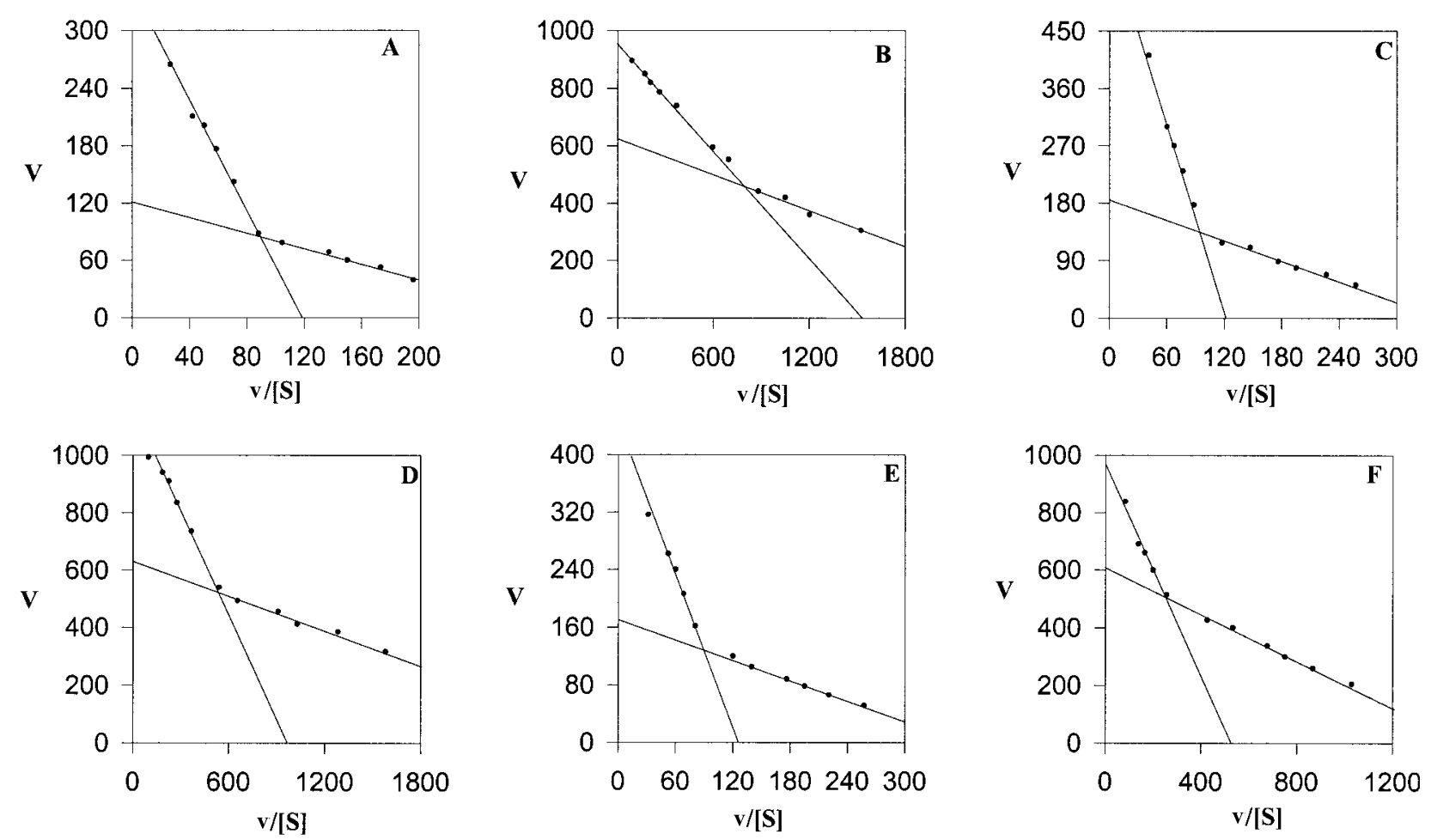

Figure 1 Typical Eadie-Hofstee plots for the rat serum BChE for (A) control male, (B) control female, (C) diabetic male, (D) diabetic female, $(E)$ insulin-treated diabetic male and $(F)$ insulin-treated diabetic female rats. Experimental details are given in the text. For determination of substrate kinetics of BChE, BCTI was used as the substrate over a concentration range of 0.05-10 mM. The ordinate represents the reaction velocity $(\mathrm{v})$, while the abscissa represents the $\mathrm{v} /[\mathrm{S}]$ ratios. Reaction velocity $=\mathrm{nmol} / \mathrm{min} \mathrm{per} \mathrm{mg} \mathrm{protein}$. $\mathrm{v} /[\mathrm{S}]=$ reaction velocity divided by the corresponding substrate concentration.

properties of serum BChE under different experimental conditions. Typical Eadie-Hofstee plots for serum BChE for male and female rats are shown in Fig. 1 from which it can be inferred that two components of $\mathrm{BChE}$ are present in the serum of male and female rats from all three experimental groups. The presence of two components of BChE was confirmed by plotting Eadie-Hofstee plots for the data following the Michaelis-Menten kinetic equation for two enzymes acting on the same substrate: $\mathrm{v}=\left(\mathrm{V}_{\max } 1 \times[\mathrm{S}] /\left(K_{\mathrm{m}} 1+[\mathrm{S}]\right)\right)+\left\{\mathrm{V}_{-\max } 2 \times[\mathrm{S}] /\left(K_{\mathrm{m}} 2+[\mathrm{S}]\right)\right.$. Data in Table 3 show $K_{\mathrm{m}}$ and $\mathrm{V}_{\max }$ values derived from substrate kinetic analysis for serum BChE from the male and female rats.

The $K_{\mathrm{m}}$ of component II was higher in male $(65 \%$, $P<0 \cdot 05)$ and female $(53 \%, P<0 \cdot 05)$ diabetic rats when compared with the corresponding control groups. The insulin treatment was able to rectify this defect in animals of both sexes. In diabetic male rats, the $\mathrm{V}_{\max }$ of components I and II was higher by $63 \%(P<0 \cdot 05)$ and $144 \%$ $(P<0 \cdot 005)$ respectively when compared with the male controls. In the males after insulin treatment, the $\mathrm{V}_{\max }$ of component II remained higher by $65 \%(P<0 \cdot 005)$ when compared with the control males. However, the $\mathrm{V}_{\max }$ of component II decreased by $27 \%(P<0 \cdot 05)$ as compared with the male diabetics, but was still about $80 \%(P<0 \cdot 005)$ higher than in the control males. No statistical differences were observed in the $\mathrm{V}_{\max }$ of components I and II in all three female experimental groups.

In brief, the $\mathrm{V}_{\text {max }}$ of both components increased in male diabetic rats and remained elevated after insulin treatment, while in the females the $\mathrm{V}_{\max }$ of both the components were comparable among all three experimental groups; i.e. the diabetic state or insulin treatments had no effect.

\section{Effect of alloxan-induced diabetes on heart weight}

It was of interest to note the weight of the heart in all the experimental groups. A statistically non-significant decreasing trend $(23 \%)$ was observed in heart weight in diabetic males (Table 1). In insulin-treated diabetic males, the heart weight increased by $30 \%(P<0 \cdot 005)$ and was comparable with the control males. The heart weight when expressed as percent of body weight was comparable among all three experimental groups. In control female rats, the heart weight was lower by $33 \%$ as compared with the control male rats (Table 1). The heart weights were 
Table 3 Effect of alloxan-induced diabetes on substrate kinetics $\left(K_{m}, m M ; V_{\max }, n m o l / m i n\right.$ per $\mathrm{ml}$ serum) of serum BChE in male and female rats. Results are expressed as means \pm S.E.M. of the number of independent observations indicated in parentheses

\begin{tabular}{|c|c|c|c|c|c|}
\hline & & Component & & Component & \\
\hline & Group & $\mathrm{K}_{\mathrm{m}}$ & $\mathrm{V}_{\max }$ & $\mathrm{K}_{\mathrm{m}}$ & $\mathrm{V}_{\max }$ \\
\hline Sex & & & & & \\
\hline Male & Control (9) & $0.49 \pm 0.06$ & $146 \pm 14$ & $2 \cdot 2 \pm 0 \cdot 19$ & $264 \pm 13$ \\
\hline & Diabetic (10) & $0.51 \pm 0.08$ & $237 \pm 35^{*}$ & $3 \cdot 6 \pm 0 \cdot 48^{*}$ & $644 \pm 57^{* *}$ \\
\hline & $\begin{array}{l}\text { Insulin-treated } \\
\text { diabetic (7) }\end{array}$ & $0 \cdot 31 \pm 0 \cdot 07$ & $240 \pm 23^{* *}$ & $2 \cdot 3 \pm 0 \cdot 36$ & $471 \pm 39^{* * a}$ \\
\hline Female & Control (8) & $0 \cdot 34 \pm 0.05$ & $708 \pm 81$ & $1 \cdot 1 \pm 0 \cdot 12$ & $1049 \pm 107$ \\
\hline & Diabetic (10) & $0 \cdot 32 \pm 0 \cdot 05$ & $601 \pm 105$ & $1 \cdot 7 \pm 0 \cdot 24^{*}$ & $1020 \pm 142$ \\
\hline & $\begin{array}{l}\text { Insulin-treated } \\
\text { diabetic (6) }\end{array}$ & $0 \cdot 27 \pm 0.03$ & $698 \pm 56$ & $1 \cdot 3 \pm 0 \cdot 14$ & $1062 \pm 65$ \\
\hline
\end{tabular}

${ }^{*} P<0.05$ and ${ }^{*} P<0.005$ compared with corresponding control value; ${ }^{a} P<0.05$ compared with corresponding diabetic value.

Table 4 BChE activity ( $\mathrm{nmol} / \mathrm{min}$ per mg protein) in soluble and membrane-bound fractions of rat heart. BCTI ( $4 \mathrm{mM})$ was used as substrate in the assay. Results are expressed as means \pm S.E.M. of the number of independent observations indicated in parentheses

\begin{tabular}{|c|c|c|c|c|}
\hline & Sex & Control & Diabetic & $\begin{array}{l}\text { Insulin-treated } \\
\text { diabetic }\end{array}$ \\
\hline \multicolumn{5}{|l|}{ Fraction of heart } \\
\hline \multirow[t]{2}{*}{ Soluble } & Male & $16 \pm 1(8)$ & $45 \pm 2(8)^{\star *}$ & $76 \pm 2(11)^{\star \star b}$ \\
\hline & Female & $52 \pm 2(8)$ & $42 \pm 2(8)^{*}$ & $74 \pm 3(9)^{* * b}$ \\
\hline \multirow[t]{2}{*}{ Membrane-bound } & Male & $61 \pm 2(6)$ & $136 \pm 6(8)^{* *}$ & $173 \pm 7(9)^{\star \star b}$ \\
\hline & Female & $77 \pm 3(6)$ & $100 \pm 6(8)^{* *}$ & $129 \pm 9(11)^{\star \star a}$ \\
\hline
\end{tabular}

${ }^{*} P<0.05$ and ${ }^{* *} P<0.005$ compared with corresponding control; ${ }^{a} P<0.05$ and ${ }^{b} P<0.005$ compared with corresponding diabetic group.

comparable in control and diabetic females. In females, after insulin treatment the heart weight increased by $46 \%$ $(P<0 \cdot 005)$ and $42 \%(P<0 \cdot 005)$ as compared with the control and diabetic females respectively. In diabetic females, the heart weight, when expressed as percent of body weight, was higher by $29 \%(P<0 \cdot 005)$ as compared with the control females. The heart weight, when expressed as percent of body weight, further increased (10\%) after insulin treatment as compared with the diabetic female rats although this increase was not statistically significant. Compared with the control females the increase was $42 \%(P<0 \cdot 005)$ in the insulin-treated diabetic females.

In brief, the control female hearts were smaller than the hearts of control males. The values of heart weight and heart weight as percent of body weight revealed an increased size of the heart in diabetic and insulin-treated diabetic females when compared with the control females; this was not true for the males.

\section{Effect of alloxan-induced diabetes on BChE activities in} soluble and membrane-bound fractions of rat heart

In both males and females, the major portion of the enzyme (in terms of enzyme activity) was present in the membrane-bound fraction as compared with the soluble fraction (Table 4). In the control females, the enzyme activities were higher by $230 \%$ and $26 \%$ in the soluble and membrane-bound fractions respectively, as compared with the control males. In the diabetic male rats, BChE activity in the soluble fraction was higher by $186 \%(P<0 \cdot 005)$ when compared with the controls. After insulin treatment of the diabetic male rats, the $\mathrm{BChE}$ activity in the soluble fraction further increased and remained elevated, while in the diabetic females the BChE activity in the soluble fraction was lower by $20 \%(P<0 \cdot 05)$ when compared with the female controls. However, after insulin treatment BChE activity increased by $41 \%(P<0 \cdot 005)$ and $77 \%$ $(P<0 \cdot 005)$ as compared with the control and diabetic females respectively.

In male rats, an almost similar effect was observed in the membrane-bound fraction of BChE under diabetic and insulin-treated diabetic conditions as in the case of the soluble fraction. A similar pattern was obtained for $\mathrm{BChE}$ activity in the membrane-bound fraction in the female rats. However, the magnitude of increase in the $\mathrm{BChE}$ activity in the membrane-bound fraction was lower in the females when compared with the males.

Except in the case of the soluble fraction of cardiac $\mathrm{BChE}$ from diabetic female rats, in general, cardiac $\mathrm{BChE}$ 

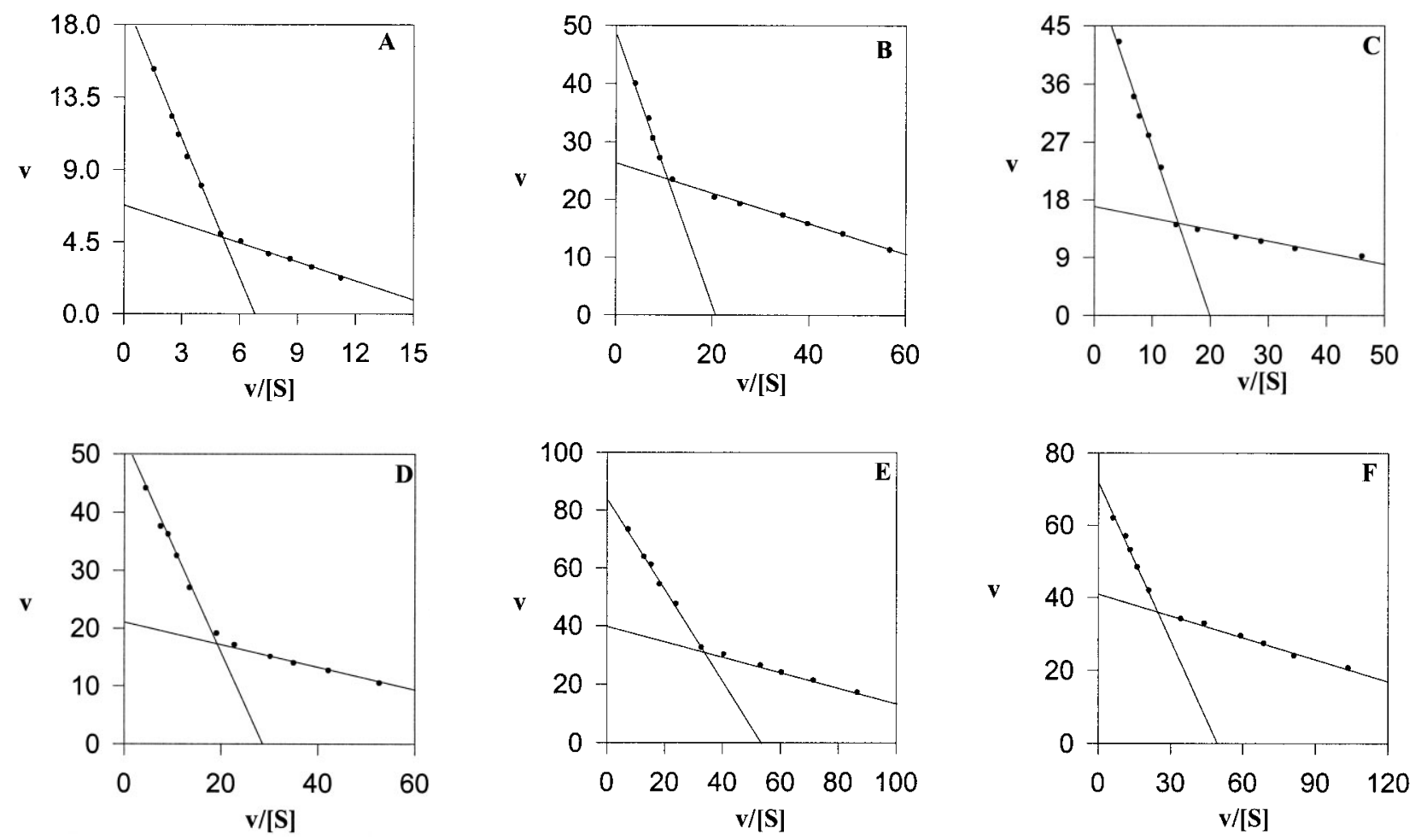

Figure 2 Typical Eadie-Hofstee plots for the rat heart soluble form of BChE for (A) control male, (B) control female, (C) diabetic male, (D) diabetic female, (E) insulin-treated diabetic male and $(F)$ insulin-treated diabetic female rats. Experimental details are given in the text. For determination of substrate kinetics of BChE, BCTI was used as the substrate over a concentration range of $0 \cdot 2-10 \mathrm{mM}$. The ordinate represents the reaction velocity $(\mathrm{v})$, while the abscissa represents the $\mathrm{v} /[\mathrm{S}]$ ratios. Reaction velocity $=\mathrm{nmol} / \mathrm{min} \mathrm{per} \mathrm{mg} \mathrm{protein}$. $\mathrm{v} /[\mathrm{S}]=$ reaction velocity divided by the corresponding substrate concentration.

activity was found to be elevated in the diabetic condition, and it was further increased in the insulin-treated rats. The magnitude of the increases was higher in the males as compared with the female rats.

\section{Effect of alloxan-induced diabetes on the substrate kinetics of} $B C h E$ from soluble and membrane-bound fraction of rat heart

In view of the drastic increase in cardiac BChE activity, it was of interest to study the effect of the alloxan-induced and insulin-treated alloxan-induced diabetic conditions on substrate kinetic properties of the soluble and membranebound fractions of cardiac BChE. Eadie-Hofstee plots for substrate kinetics of $\mathrm{BChE}$ from the soluble fraction of male and female rat heart are given in Fig. 2, while Fig. 3 shows typical Eadie-Hofstee plots for substrate kinetics of the membrane-bound fraction of cardiac BChE in the male and female rats. The pattern shows the presence of two components of BChE in both fractions (Figs 2 and 3). This was the same in the case of serum enzyme, where the presence of two components of BChE was confirmed by plotting Eadie-Hofstee plots for the data using the Michaelis-Menten kinetic equation for two enzymes act- ing on the same substrate. Data in Table 5 give the $K_{\mathrm{m}}$ and $\mathrm{V}_{\max }$ values derived from the substrate kinetics analysis of BChE in both fractions.

In diabetic males, the $K_{\mathrm{m}}$ of component I of BChE from the soluble fraction of the heart decreased by $44 \%$ $(P<0.005)$ as compared with the control males, while the $K_{\mathrm{m}}$ of component II was comparable among the diabetic and control male groups. The $\mathrm{V}_{\max }$ of both components I and II increased by $173 \%(P<0 \cdot 005)$ and $211 \%(P<0 \cdot 005)$ respectively when compared with the control males. After insulin treatment, the $K_{\mathrm{m}}$ of component I was still lower $(39 \%, P<0 \cdot 005)$ as compared with the control values, and the $K_{\mathrm{m}}$ of component II also decreased by $35 \%$ as compared with both the control $(P<0 \cdot 005)$ and diabetic $(P<0.005)$ males. Insulin treatment also resulted in a statistically significant further increase in the $\mathrm{V}_{\max }$ of both components.

In the diabetic condition, only the $K_{\mathrm{m}}$ of component II of $\mathrm{BChE}$ from the soluble fraction of the heart decreased by $21 \%(P<0 \cdot 005)$ when compared with the control females; even after insulin treatment the $K_{\mathrm{m}}$ of component II was the same as in the diabetic group. In females, the diabetic condition had no effect on the $\mathrm{V}_{\max }$ of both 

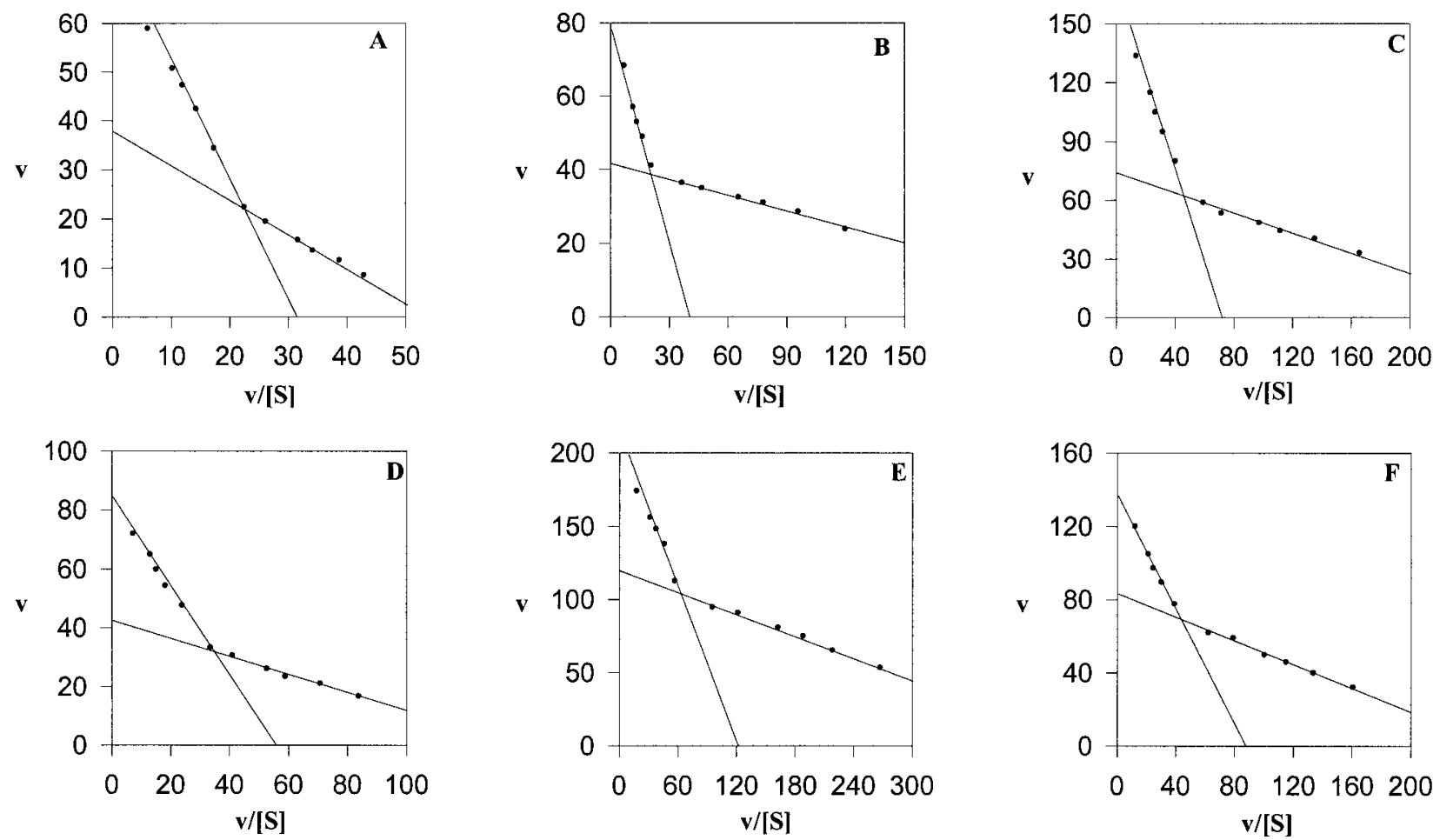

Figure 3 Typical Eadie-Hofstee plots for the rat heart membrane-bound fraction of BChE for (A) control male, (B) control female, (C) diabetic male, (D) diabetic female, (E) insulin-treated diabetic male and (F) insulin-treated diabetic female rats. Experimental details are given in the text. For determination of substrate kinetics of BChE, BCTI was used as the substrate over a concentration range of $0 \cdot 2-10 \mathrm{mM}$. The ordinate represents the reaction velocity $(\mathrm{v})$, while the abscissa represents the $\mathrm{v} /[\mathrm{S}]$ ratios. Reaction velocity $=\mathrm{nmol} / \mathrm{min}$ per mg protein. $\mathrm{v} /[\mathrm{S}]=$ reaction velocity divided by the corresponding substrate concentration.

Table 5 Substrate kinetics $\left(\mathrm{K}_{\mathrm{m}}, \mathrm{nM} ; \mathrm{V}_{\max }, \mathrm{nmol} / \mathrm{min}\right.$ per $\mathrm{mg}$ protein) of soluble and membrane-bound form of cardiac BChE in male and female rats. Results are expressed as means \pm S.E.M. of the number of independent observations indicated in parentheses

\begin{tabular}{|c|c|c|c|c|c|c|}
\hline & \multirow[b]{2}{*}{ Sex } & \multirow[b]{2}{*}{ Group } & \multicolumn{2}{|l|}{ Component I } & \multicolumn{2}{|l|}{ Component II } \\
\hline & & & $\mathrm{K}_{\mathrm{m}}$ & $\mathrm{V}_{\max }$ & $\mathrm{K}_{\mathrm{m}}$ & $\mathrm{V}_{\max }$ \\
\hline \multicolumn{7}{|l|}{ Fraction of heart } \\
\hline \multirow[t]{6}{*}{ Soluble } & Male & Control (8) & $0 \cdot 31 \pm 0.03$ & $6 \pm 0 \cdot 3$ & $2 \cdot 3 \pm 0 \cdot 2$ & $17 \pm 1 \cdot 5$ \\
\hline & & Diabetic (8) & $0 \cdot 17 \pm 0 \cdot 01^{* *}$ & $17 \pm 0 \cdot 9^{\star *}$ & $2 \cdot 3 \pm 0 \cdot 1$ & $53 \pm 3 \cdot 0^{* *}$ \\
\hline & & $\begin{array}{l}\text { Insulin-treated } \\
\text { diabetic (11) }\end{array}$ & $0 \cdot 19 \pm 0 \cdot 01^{* *}$ & $41 \pm 3 \cdot 1^{\star * b}$ & $1 \cdot 5 \pm 0 \cdot 1^{* \star b}$ & $87 \pm 2 \cdot 6^{* * b}$ \\
\hline & Female & Control (8) & $0.25 \pm 0.03$ & $23 \pm 1 \cdot 3$ & $2 \cdot 2 \pm 0 \cdot 1$ & $54 \pm 1 \cdot 9$ \\
\hline & & Diabetic (8) & $0 \cdot 26 \pm 0.03$ & $24 \pm 1 \cdot 8$ & $1 \cdot 7 \pm 0 \cdot 1^{*}$ & $48 \pm 2 \cdot 0$ \\
\hline & & $\begin{array}{l}\text { Insulin-treated } \\
\text { diabetic (9) }\end{array}$ & $0 \cdot 18 \pm 0 \cdot 02$ & $43 \pm 3 \cdot 9^{* \star b}$ & $1 \cdot 6 \pm 0 \cdot 1^{* *}$ & $82 \pm 3 \cdot 5^{\star * b}$ \\
\hline \multirow[t]{6}{*}{ Membrane-bound } & Male & Control (6) & $0.59 \pm 0.09$ & $39 \pm 4 \cdot 2$ & $2 \cdot 5 \pm 0 \cdot 2$ & $81 \pm 4 \cdot 1$ \\
\hline & & Diabetic (8) & $0 \cdot 24 \pm 0.03^{* *}$ & $69 \pm 3 \cdot 1^{* *}$ & $2 \cdot 1 \pm 0 \cdot 1$ & $161 \pm 6 \cdot 1^{* *}$ \\
\hline & & $\begin{array}{l}\text { Insulin-treated } \\
\text { diabetic (11) }\end{array}$ & $0 \cdot 35 \pm 0 \cdot 04^{\star a}$ & $120 \pm 4 \cdot 9 * * b$ & $1 \cdot 6 \pm 0 \cdot 2^{\star a}$ & $206 \pm 10 \cdot 6^{* \star b}$ \\
\hline & Female & Control (6) & $0 \cdot 18 \pm 0 \cdot 01$ & $40 \pm 0 \cdot 8$ & $1 \cdot 9 \pm 0 \cdot 1$ & $84 \pm 3 \cdot 8$ \\
\hline & & Diabetic (8) & $0 \cdot 36 \pm 0.03^{*}$ & $64 \pm 4 \cdot 3^{* *}$ & $1 \cdot 8 \pm 0 \cdot 1$ & $108 \pm 7 \cdot 4^{*}$ \\
\hline & & $\begin{array}{l}\text { Insulin-treated } \\
\text { diabetic }(9)\end{array}$ & $0 \cdot 28 \pm 0.03^{*}$ & $88 \pm 7 \cdot 8^{\star * a}$ & $1 \cdot 5 \pm 0 \cdot 1^{\star a}$ & $143 \pm 10 \cdot 1^{\text {**a }}$ \\
\hline
\end{tabular}


components of the soluble form of cardiac BChE when compared with the control females. After insulin treatment, the $\mathrm{V}_{\max }$ of component I increased by $85 \%$ $(P<0.005)$ and $78 \%(P<0.005)$ as compared with the control and diabetic females respectively. A similar picture was true for the $\mathrm{V}_{\max }$ of component II. After insulin treatment, the $\mathrm{V}_{\max }$ of component II increased by $53 \%$ $(P<0.005)$ and $71 \%(P<0.005)$ as compared with the control and diabetic female rats respectively.

In the diabetic male rats, the $K_{\mathrm{m}}$ of component I of the membrane-bound form of cardiac BChE decreased by $59 \%(P<0 \cdot 005)$ when compared with the control males. The $\mathrm{V}_{\max }$ of both components of the membrane-bound form of cardiac BChE increased by 74\% $(P<0 \cdot 005)$ and $99 \%(P<0 \cdot 005)$ respectively as compared with the control male rats. After insulin treatment, the $K_{\mathrm{m}}$ of component I of the membrane-bound form of cardiac BChE increased by $47 \%(P<0 \cdot 05)$ when compared with the diabetic males, but was still lower by $40 \%(P<0 \cdot 05)$ when compared with the control males. Interestingly, after insulin treatment, the $K_{\mathrm{m}}$ of component II decreased by $34 \%(P<0 \cdot 05)$ and $24 \%$ $(P<0 \cdot 05)$ as compared with the control and diabetic males respectively. The $\mathrm{V}_{\max }$ of components I and II increased further by $75 \%(P<0 \cdot 005)$ and $28 \%(P<0 \cdot 005)$ after insulin treatment respectively when compared with the diabetic male rats. The $\mathrm{V}_{\max }$ values of components $\mathrm{I}$ and II remained higher by $205 \%(P<0 \cdot 005)$ and $154 \%(P<0 \cdot 005)$ in the insulin-treated males respectively when compared with the control males.

The influence of the diabetic and insulin-treated diabetic conditions was dramatically different on $\mathrm{BChE}$ activities in the membrane-bound fraction of the female rat heart as compared with males. In the control group, the $K_{\mathrm{m}}$ of component I was about three times lower compared with the control males, while the $\mathrm{V}_{\max }$ was comparable in both sexes. Also for component II, the $K_{\mathrm{m}}$ was lower $(22 \%)$ in control females as compared with the control males, while the $\mathrm{V}_{\max }$ values were comparable in both sexes. In the diabetic state, $K_{\mathrm{m}}$ and $\mathrm{V}_{\max }$ of component I almost doubled while the $\mathrm{V}_{\max }$ of component II increased by $29 \%(P<0 \cdot 05)$. After insulin treatment, the $K_{\mathrm{m}}$ of component I decreased somewhat but was still higher $(50 \%, P<0 \cdot 05)$ than the control females. After insulin treatment, the $K_{\mathrm{m}}$ of component II decreased by $21 \%$ $(P<0 \cdot 05)$ and $16 \%(P<0 \cdot 05)$ respectively when compared with the control and diabetic female groups. The $\mathrm{V}_{\max }$ of component I further increased after insulin treatment by $38 \%(P<0.05)$ as compared with the diabetic female rats and remained $2 \cdot 2$-fold $(P<0 \cdot 005)$ higher as compared with the control female rats. A similar pattern was obtained for the $\mathrm{V}_{\max }$ of component II. However, the extent of increase was much less compared with the corresponding males (Table 5).

In brief, the variable effects of the diabetic and insulintreated diabetic conditions were observed on $K_{\mathrm{m}}$ values in both fractions of both sexes. The value of $\mathrm{V}_{\max }$ in general increased in the diabetic condition in both fractions of both sexes; this further increased in the insulin-treated diabetic condition. In general, the magnitude of increase was higher in the males when compared with the females.

\section{Discussion}

In the present study, the alloxan-induced diabetic condition was confirmed by polyuria, glycosuria, hyperglycemia and loss of body weight. The present insulin treatment regime was able to control these characteristics of diabetes.

Sex differences in serum and cardiac BChE activity were observed. The sex difference in the BChE activity was more prominent in the serum and soluble fraction of rat heart when compared with the cardiac membranebound fraction. Sex differences in plasma and liver BChE activity have been reported previously (Lamartiniere 1986, Oreskovic \& Kunec-Vajic 1992). It has been suggested that the sex difference is caused by estrogen, which at the level of the pituitary gland regulates the pattern of secretion of growth hormone $(\mathrm{GH})$, which in turn acts on the hepatocytes and promotes the synthesis of $\mathrm{BChE}$ (Cammisa et al. 1988). However, the effect of GH on the synthesis of BChE is controversial (Lamartiniere 1986, Cammisa et al. 1988).

In the diabetic male rats, an increase of the $\mathrm{BChE}$ activity in the serum, soluble and membrane-bound fractions of the heart was evident when compared with the control males; while, in the diabetic females, the increase in BChE activity was evident only in the membranebound fraction of the heart when compared with the control females. The BChE activity was found to be increased in serum, soluble and membrane-bound fractions of the heart in the insulin-treated groups of both sexes.

It has been shown that diabetic rat hearts do not respond to conditions of high stress when compared with controls (Tahiliani \& McNeill 1986). Cardiac muscle cells in the streptozotocin-induced diabetic rat heart showed condensation of molecular chromatin and folding of nuclear membranes. Swelling of mitochondria, clearing of mitochondrial matrix and incorporation of lysosomal membranes into mitochondrial matrix were noted (Seager et al. 1984). A marked increase in both lysosomes and lipid droplets was apparent (Seager et al. 1984).

As has been mentioned in the Introduction, the source of the high levels of serum $\mathrm{BChE}$ under diabetic conditions is not known. The effect of diabetes on cardiac $\mathrm{BChE}$ has not been studied so far despite high BChE levels in the heart. For easy comparison between the $\mathrm{BChE}$ of serum and heart we studied the substrate kinetics of this enzyme in both tissues.

Except for the increase in the $K_{\mathrm{m}}$ of component II of serum BChE in the diabetic females, no statistically 
significant changes were evident in serum $\mathrm{BChE}$ in the diabetic and insulin-treated diabetic female rats. In males, a high $K_{\mathrm{m}}$ of component II of serum BChE was also evident. In diabetic males, the increase in the $\mathrm{V}_{\max }$ of component I was of lesser magnitude (65\% increase) than the increase in the $\mathrm{V}_{\max }$ of component II (144\% increase). A similar picture was also observed in the insulin-treated diabetic male rats. Thus the data indicated that the increase in the $\mathrm{V}_{\max }$ of component II may be a key player for high serum BChE activity in the diabetic and insulintreated diabetic males. Interestingly, the $K_{\mathrm{m}}$ of component II of the soluble and membrane-bound forms of cardiac $\mathrm{BChE}$ was comparable with the $K_{\mathrm{m}}$ of component II of serum BChE.

When considering the cardiac BChE data in terms of ratios of specific activity of soluble to membrane-bound forms, the ratio of the soluble to membrane-bound form of the enzyme was 0.26 in control males but was much higher, i.e. $0 \cdot 68$, in the control females. In the diabetic males, the ratio increased slightly, e.g. $0 \cdot 33$, and the trend toward increased ratios continued $(0 \cdot 44)$ in the insulintreated diabetic males. In the females under all the conditions, the ratio was always higher than in the corresponding males $(0.68,0.42$ and 0.57 for control, diabetic and insulin-treated diabetic groups respectively).

From the activity data, substrate kinetics of serum and cardiac BChE and the ratio of soluble to membrane-bound forms of cardiac BChE activity, it can be hypothesized that under diabetes-induced cardiac pathology the proportion of the soluble form of cardiac BChE increases. High levels of the soluble form of cardiac $\mathrm{BChE}$ could be a possible source of the increased level of serum BChE under the diabetic condition. Increase in cardiac BChE activity in diabetic and insulin-treated diabetic male rats could be a compensatory mechanism. No increase was found in the cardiac BChE activity in diabetic female rats, which could be the reason for the high incidence of mortality due to cardiovascular causes in diabetic females.

At present we are able to control the physiological parameters of diabetes by insulin treatment of diabetic rats. Insulin treatment was not able to improve most of the diabetes-induced alterations in BChE from all the sources studied. Insulin treatment is known to control blood sugar levels but is not able to rectify all the lipid defects (Romano et al. 1997). Ido et al. (1997) have shown that not all the maladies of diabetes can be corrected by insulin treatment.

In conclusion, basic sex differences were observed in serum and cardiac BChE in rats. The effect of diabetes on serum and cardiac BChE was also sex dependent. Insulin was not able to rectify the diabetes-induced abnormalities in serum and cardiac BChE. The heart could be one of the possible sources of the increased level of serum BChE. Alterations in cardiac BChE could be one of the reasons behind the high incidences of coronary heart disease and congestive heart failure in diabetics.

\section{Acknowledgements}

This study was supported by a scholarship awarded to KRD by the Lady Tata Memorial Trust, Mumbai (Bombay), India.

\section{References}

Abbott CA, Mackness MI, Kumar S, Olukoga AO, Gordon C, Arrol S, Bhatnagar D, Boulton AJ \& Durrington PN 1993 Relationship between serum butyrylcholinesterase activity, hypertriglyceridaemia and insulin sensitivity in diabetes mellitus. Clinical Science 85 77-81.

Annapurna V, Senciall I, Davis AJ \& Kutty KM 1991 Relationship between serum pseudocholinesterase and triglycerides in experimentally induced diabetes mellitus in rats. Diabetologia 34 320-324.

Bahnak BR \& Gold AH 1982 Effects of alloxan diabetes on the turnover of rat liver glycogen synthase. Comparison with liver phosphorylase. Journal of Biological Chemistry 257 8775-8780.

Bisso GM, Briancesco R \& Michalek H 1991 Size and charge isomers of acetylcholinesterase in the cerebral cortex of young and aged rats. Neurochemical Research 16 571-575.

Cammisa HM, Isom HC \& Greene FE 1988 Hormonal regulation of pseudocholinesterase activity in cultured rat hepatocytes. Endocrinology 122 991-996.

Chatonnet A \& Lockridge O 1989 Comparison of butyrylcholinesterase and acetylcholinesterase. Biochemical Journal $260625-634$.

Chu MI, Fontaine P, Kutty KM, Murphy D \& Redheendran R 1978 Cholinesterase in serum and low density lipoprotein of hyperlipidemic patients. Clinica Chimica Acta 85 55-59.

Cucuianu M, Popescu TA, Opincaru A \& Haragus S 1975 Serum pseudocholinesterase and ceruloplasmin in various types of hyperlipoproteinemia. Clinica Chimica Acta 59 19-27.

Dave KR, Syal AR \& Katyare SS 2000 Tissue cholinesterases. A comparative study of their kinetic properties. Zeitschrift für Naturforschung C 55 100-108.

Dave KR, Syal AR \& Katyare SS 2002 Effect of long-term aluminum feeding on kinetics attributes of tissue cholinesterases. Brain Research Bulletin 58 225-233.

Dixon M \& Webb C 1979 Enzymes, pp 47-206. London: Longman.

Ellman GL, Courtney KV, Anders V \& Featherstone RM 1961 A new and rapid colorimetric determination of acetylcholinesterase activity. Biochemical Pharmacology 7 88-95.

Funnel HS \& Oliver WT 1965 Proposed physiological function for plasma cholinesterase. Nature 208689.

Ido Y, Vindigni A, Chang K, Stramm L, Chance R, Heath WF, DiMarchi RD, Di Cera E \& Williamson JR 1997 Prevention of vascular and neural dysfunction in diabetic rats by $\mathrm{C}$-peptide. Science 277 563-566.

Kutty KM 1980 Biological function of cholinesterase. Clinical Biochemistry 13 239-243.

Kutty KM, Huang SN \& Kean KT 1981 Pseudocholinesterase in obesity: hypercaloric diet induced changes in experimental obese mice. Experientia 37 1141-1142.

Lamartiniere CA 1986 Growth hormone modulates serum cholinesterase. Endocrinology 118 1252-1254.

Lockridge O, Mottershaw-Jackson N, Eckerson HW \& La Du BN 1980 Hydrolysis of diacetylmorphine (heroin) by human serum cholinesterase. Journal of Pharmacology and Experimental Therapeutics $2151-8$.

Lowry OH, Rosebrough NJ, Farr AL \& Randall RJ 1951 Protein measurement with the Folin phenol reagent. Journal of Biological Chemistry 193 265-275.

Magarian EO \& Dietz AJ 1987 Correlation of cholinesterase with serum lipids and lipoproteins. Journal of Clinical Pharmacology 27 $819-820$. 
Massoulie J, Pezzementi L, Bon S, Krejci E \& Vallette FM 1993 Molecular and cellular biology of cholinesterases. Progress in Neurobiology 41 31-91.

Nerurkar MA, Satav JG \& Katyare SS 1988 Insulin-dependent changes in lysosomal cathepsin D activity in rat liver, kidney, brain and heart. Diabetologia 31 119-122.

Oreskovic K \& Kunec-Vajic E 1992 Pseudocholinesterase in alloxandiabetic rats. Research Communications in Chemical Pathology and Pharmacology 78 117-120.

Patel BN, Mackness MI, Harty DW, Arrol S, Boot-Handford RP \& Durrington PN 1990 Serum esterase activities and hyperlipidaemia in the streptozotocin-diabetic rat. Biochimica et Biophysica Acta 1035 113-116.

Romano G, Patti L, Innelli F, Di Marino L, Annuzzi G, Iavicoli M, Coronel GA, Riccardi G \& Rivellese AA 1997 Insulin and sulfonylurea therapy in NIDDM patients. Are the effects on lipoprotein metabolism different even with similar blood glucose control? Diabetes 46 1601-1606.

Seager MJ, Singal PK, Orchard R, Pierce GN \& Dhalla NS 1984 Cardiac cell damage: a primary myocardial disease in streptozotocininduced chronic diabetes. British Journal of Experimental Pathology 65 613-623.
Shirai K, Ohsawa I, Saito Y \& Yoshida S 1988 Effects of phospholipids on hydrolysis of trioleoylglycerol by human serum carboxylesterase. Biochimica et Biophysica Acta 962 377-383.

Shirai K, Inadera K, Kurosawa H, Saito Y \& Yoshida S 1991 Cholesterol ester hydrolyzing activity by pseudocholinesterase (PchE) and its role in lipoprotein metabolism (Abstract). In Cholinesterases. Structure, Function, Mechanism, Genetics and Cell Biology, pp 374. Eds J Massoulie, F Bacou, E Barnard, A Chatonnet, BP Doctor \& DM Quinn. Washington DC: American Chemical Society.

Tahiliani AG \& McNeill JH 1986 Diabetes-induced abnormalities in the myocardium. Life Sciences 38 959-974.

Valentino RJ, Lockridge O, Eckerson HW \& La Du BN 1981 Prediction of drug sensitivity in individuals with atypical serum cholinesterase based on in vitro biochemical studies. Biochemical Pharmacology 30 1643-1649.

Received in final form 11 June 2002 Accepted 2 July 2002 